\title{
DULCE MARÍA BORRERO: UNA INTELECTUAL PLURAL
}

\author{
Yolanda Ricardo ${ }^{1}$ \\ Universidad de La Habana (Cuba) \\ Grupo de investigación HISULA \\ yolr@infomed.sld.cu
}

Recepción: 17/06/2012

Evaluación: 04/07/2012

Aceptación: 03/11/2012

Artículo de Reflexión

DOI: http:/ / dx.doi.org/ 10.9757/ Rhela.20.01

\section{RESUMEN}

Este artículo constituye una reflexión basada en informaciones procedentes de una investigación asumida desde una perspectiva socio histórica, con metodología analítica, interpretativa y crítica sobre la personalidad polifacética de la intelectual cubana Dulce María Borrero. Tiene como propósito esencial ofrecer su perfil intelectual contextualizado y enfatizar en sus contribuciones a la educación republicana de la primera mitad del siglo XX en Cuba, básicamente en el nivel primario en estrecha interacción con el proceso socioeducativo cubano de su tiempo.

Palabras clave: Revista Historia de la Educación Latinoamericana, educación primaria, escuela pública, escuela nueva, escuela rural, magisterio, identidad.

1 Doctora en Ciencias sobre el Arte, Doctora en Filosofía. Profesora Titular de la Universidad de La Habana, Investigadora Titular del Sistema Nacional de Ciencias de Cuba, Miembro de la Academia de Ciencias de República Dominicana, del Claustro internacional de la Universidad de Bretaña Occidental en Francia, del Grupo de Investigación Historia y Prospectiva de la Universidad Latinoamericana (HISULA) de Colombia, adscrito a la Universidad Pedagógica y Tecnológica de Colombia, del Comité Científico de la Revista Historia de la Educación Latinoamericana, de la Junta Directiva de la Sociedad de Historia de la Educación Latinoamericana (SHELA) y de la Unión Nacional de Escritores y Artistas de Cuba (UNEAC). 


\section{DULCE MARÍA BORRERO:}

A DIVERSE INTELLECTUAL

\section{ABSTRACT}

This article is a reflection based on information from research undertaken from a socio-historical perspective with analytical, interpretive and critical methodology; it is about the multifaceted personality of the Cuban intellectual Dulce María Borrero. The essential purpose is to provide her intellectual profile in the context and emphasize her contributions to the Republican education of the first half of twentieth century in Cuba, mainly at the primary level, in close interaction with the Cuban socio-educational process of her time.

Key words: History of Latin American Education Journal, primary, public school, new school, rural school teachers, identity.

\section{DULCE MARÍA BORRERO: \\ UMA INTELECTUAL PLURAL}

RESUMO

Este artigo consiste numa reflexão baseada em informações procedentes de uma pesquisa realizada sob uma perspectiva sócia histórica, com metodologia analítica, interpretativa e crítica sobre a personalidade multifacetada da intelectual cubana Dulce María Borrero. Tem o propósito essencial de apresentar seu perfil intelectual contextualizado e enfatizar em suas contribuições a educação republicana da primeira metade do século XX em Cuba, basicamente no nível primário, em estreita interação com o processor socioeducativo cubano de seu tempo.

Palavras-chave: Revista História da Educação Latino-americana, educação primária, escola pública, escola nova, escola rural, magistério, identidade.

\title{
INTRODUCCIÓN
}

\author{
Revolucionen, pues: \\ establezcan innovaciones \\ trascendentes para la consolidación \\ definitiva de su personalidad social, \\ que es alta y poderosa como ninguna. \\ (A los maestros, 1925)
}

La valoración de la documentación histórica primaria y especializada fundamentalmente manuscritos de la autora estudiada y textos de diferentes educadores de su etapa vital en el siglo $\mathrm{XX}_{-}$, el análisis de hechos y de procesos históricos y socioculturales, y los ineludibles tejidos interdisciplinarios posibilitan estructurar una reflexión de alcance integral sobre la personalidad de la intelectual cubana Dulce María Borrero, su condición de educadora. Puede comenzarse por aseverar que en el continente americano y particularmente en el Caribe hispánico se produjo desde el siglo anterior una

2. Dulce María Borrero, “Instrucción complementaria del maestro. Las Escuelas Normales de verano", Revista de Instrucción Pública, No. 3, (1925): 134. 
tendencia sostenida a atribuir a la educación potencialidades axiológicas y transformativas de amplio rango, desde los resortes cognitivos de la instrucción y la modelación ética y patriótica de la personalidad. Esta dirección del pensamiento será un pilar de la nacionalidad cubana desde la llamada instrucción pública, ante agresiones tan profundas como la estructuración de la educación a partir de la primera intervención militar norteamericana en $\mathrm{Cuba}^{3}$ y el injerencismo neocolonialista que perdurará hasta 1958.

Al alborear el siglo XX con los antecedentes atesorados en la lucha anticolonial durante el siglo anterior, incluida la labor de las educadoras mambisas y la de las emigradas revolucionarias, numerosas maestras de la llamada escuela pública -la de carácter estatal, laica y gratuita- unieron sus vidas al empeño nacionalista acudiendo al ideario de los mentores de la nacionalidad y muy particularmente al legado liberador y revolucionario de José Martí. De este modo, no dejará de crecer en la historia educativa cubana el registro de educadoras de estimable labor en la esfera de la identidad. Una de ellas, de peculiar resonancia, fue Dulce María Borrero (1883-1945)4.

Abordar el estudio de esta intelectual cubana, en su condición de educadora en la Cuba republicana de la primera mitad del siglo XX, es abocarse a una tarea de múltiples aristas, dada la profusa variedad de su ejecutoria vital volcada a la vida, tanto en el magisterio educativo como en el arte del verso, del color, en la promoción cultural, en el periodismo y la lucha social. Significativa fue su interacción con el proceso socioeducativo del país iniciada con docencia en la enseñanza primaria, ejercicio que le permitió enriquecer su acervo educativo y ganar en profundidad con teorizaciones sobre la práctica pedagógica en sensitivo pálpito de su propio contexto y en las relaciones con la intelectualidad de la época. Desde esta óptica, este artículo de reflexión fue estructurado en siete secciones: Introducción; Los Borrero Pierra; De 1902 a 1920: una pluralidad creciente; Años prolíficos: 1920-1939; Sus últimos cinco años; Pensamiento pedagógico y Conclusiones.

3. Ver: Louis de Pérez, El diseño imperial: política y pedagogía en el período de la ocupación de Cuba 1899-1902 (La Habana: Ministerio de Educación, 1985), 11. Este trabajo apareció primero en la Revista del Centro de Estudios Cubanos de la Universidad de Pittsburg.

4. Nació en Puentes Grandes, La Habana, el 10 de septiembre de 1883 y falleció el 15 de enero de 1945, también en La Habana. 


\section{Los Borrero Pierra}

El Caribe cuenta con varias familias como conjuntos de intelectuales que han ejercido un papel significativo en los procesos socioculturales de sus naciones: los Henríquez Ureña y los Henríquez y Carvajal, en República Dominicana; los Loynaz y los Borrero Pierra, en Cuba; los Gautier Benítez, los Tió y los de Hostos Ayala, en Puerto Rico; los Bellegarde, en Haití, entre otras. Los Borrero Pierra, con una notable ascendencia, colmaron a la cultura cubana de excelencias artísticas y otros quehaceres (científicos, pedagógicos, periodísticos, estilísticos), a los que se suma la lucha social -sobre todo de orientación feminista- que con frecuencia se entronca con el compromiso político a favor de los destinos de la nación. Y es que crecieron en la casona de Puentes Grandes, el hogar aledaño al río habanero Almendares, volcado al arte, a la educación, al periodismo y a los afanes libertarios tributarios de la identidad nacional. No faltó quien dijera, como Rubén Darío, que aquella era una familia de artistas ${ }^{5}$.

Esteban Borrero Echeverría (1849-1906), el padre, guía y conductor, fue un hombre de ciencias, educador, poeta y ensayista, quien propició la formación humanista de sus hijas y el interés en ramas particulares del arte, como el verso y la pintura, en el caso de Dulce María y Juana, la talentosa poetisa, e ícono cultural cubano. Cuando la familia parte para Cayo Hueso, el 18 de enero de $1896^{6}$ por aconsejable exilio voluntario ante las posiciones independentistas de Esteban, ya Dulce María escribía sus primeros poemas y pintaba. Ante las tareas de la emigración revolucionaria que ha asumido su padre, ella lo sigue hasta Costa Rica para convertirse en su apoyo cotidiano. Así fue forjando su carácter, entre los deberes patrios y el amor a varias manifestaciones de la cultura. En la Revista de Cayo Hueso y en Cuba y América, en donde aparecieron sus primeros versos con ilustraciones propias en 1897, queda el tono melancólico de los dolores de la familia signada por la diáspora y el duelo de la pérdida de Juana, la virgen triste, pérdida que causará honda pena para todos. Al finalizar la guerra anticolonial, regresa la familia a Cuba en 1899. Dulce María seguirá cultivando la poesía y la pintura, rutas de lo que será luego realización y logro. Y también tomará el camino de la educación.

\footnotetext{
5 Ver en Yolanda Ricardo, Nueva visión de Dulce María Borrero (La Habana: Letras Cubanas, 1983), 14, la nota 8, en la que se hace referencia al texto Los Borrero. Familia de artistas de Rubén Darío, perteneciente a sus Obras Completas, Vol. XV, (1927):167. El poeta nicaragüense subraya la condición de "familia privilegiada por el talento y las facultades artísticas".

6 Ver nota de Cintio Vitier “Epistolario”, en Juana Borrero (La Habana: Academia de Ciencias de Cuba, 1967), 262.
} 


\section{De 1902 a 1920: una pluralidad creciente}

De retorno en La Habana, Los Borrero Pierra abren sus puertas a la intelectualidad del nuevo siglo: animan las tertulias que encarnan un significativo espacio de interés para la cultura cubana, entre 1902 y 1906. Dulce María y sus hermanas beben de esas fuentes. Por allí pasan figuras notables de la lucha de liberación reciente, poetas, naturalistas, pedagogos, pintores, pianistas, editores de revistas nacionales, y extranjeros residentes o de paso por el país.

Sin lugar a dudas, el entorno familiar de Dulce María fue notablemente favorecedor para su desarrollo cultural y patriótico, así como para entregar sus empeños a la educación. En estos años finiseculares y de inicios de otro siglo despliega una intensa actividad. Comenzará su docencia en el nivel de la enseñanza primaria e ilustrará tres libros de su padre: Lectura de pascuas (1899), Don Quijote, poeta. Juguete literario (muy elogiado por Rubén Darío) ${ }^{7}$ y El amigo del niño, de 1905, este último con pequeñas escenas propias para la imaginación infantil, en correspondencia con los objetivos del autor al destinar la obra a libro de texto para los escolares cubanos. De igual forma, se adentra progresivamente en el mundo intelectual: estudia música, arte que le permite componer algunas piezas y musicalizar el Intermezzo de Heine (según refirió su hermana Mercedes); colabora con periódicos y revistas; dirige la Revista de Instrucción Pública ${ }^{8}$; es cofundadora de la Academia Nacional de Artes y Letras, a la que pertenecerá de modo vitalicio; da los primeros pasos en la lucha feminista enarbolando lanzas contra el hegemonismo patriarcal de su sociedad y continúa escribiendo versos. Su poemario Horas de mi vida alcanzará un galardón importante para la época, el Premio de la Academia Nacional de Artes y Letras (1912). Con él se propiciará la profundización de sus nexos con creadores del país y de origen foráneo, como Rubén Darío, José Enrique Rodó, José Santos Chocano, Luis G. Urbina, Gabriela Mistral, Francisco Villaespesa, Federico Henríquez y Carvajal, Américo Lugo y Fabio Fiallo, entre varios. Su referencia intelectual más importante será el símbolo de cubanía, encarnado por Enrique José Varona, a quien la

\footnotetext{
Darío, Rubén, "Obras Completas", 174.

8 La información sobre su labor ejecutiva en la Revista de Instrucción Pública procede del volante impreso con su fotografía del "Curso Los amigos de la escuela nueva", Colegio Presbiteriano Carlos de la Torre, Sancti Spíritus, que anuncia su conferencia Nuevo sentido de la misión del maestro en la Escuela Renovada, 24 de octubre de 1936. En Fondo Los Borrero (CM Borrero, No. 98) de la Biblioteca Nacional de Cuba. Esta información se confirmó en carta manuscrita que le dirige Sara Isalgué, con fecha 29 de octubre de 1918, desde Matanzas, en Fondo Los Borrero ILL (BOR-D, No. 518). No se ha podido constatar aún la información en la propia Revista por no existir ejemplares disponibles en las principales bibliotecas de la capital.
} 
unieron lazos de amistad. Posteriormente, mantendrá este mismo sentido de vida: multiplicándose, entregándose a causas nobles con mucho de espíritu martiano y heredera de los ideales de identidad que caracterizaron a la vanguardia revolucionaria de las luchas anticoloniales.

Aunque su hermana "Mercita" refirió en 1973 a la autora de este artículo que Dulce María se estrenó en la docencia de modo familiar, es preferible situar el comienzo de su práctica educativa en 1902. La acreditación de maestros emergentes -o lo que se conocería como maestros de certificado-, que validó su capacidad para ejercer la enseñanza, fue expresión de las medidas adoptadas por el gobierno de ocupación militar norteamericano (1899-1902), en la reorganización de la enseñanza en Cuba y en el intento de cubrir las nuevas exigencias de aulas creadas tras el fin de la guerra en la Isla. De modo que pudo ser contratada como maestra de primaria9 en 1902: un momento de verdadero desastre educativo y cultural, heredado de la política colonialista española, de las contingencias del enfrentamiento militar y de las acciones drásticas y antihumanas de Valeriano Weyler con un Plan de Reconcentración que costó miles de vidas a la población cubana. Cuba entró al siglo XX con un $63,91 \%$ de analfabetismo. ${ }^{10}$

Si bien ante el estado de incultura encontrado en la Isla los ocupantes militares estadounidenses organizaron desde 1899 el sistema de instrucción pública y promovieron la actualización pedagógica, marcadamente de base positivista, no todo tuvo signo de progreso, pues pusieron en vigor una tendenciosa política educacional, aparentemente civilizadora, que les permitiera entrar en vidas y conciencias, crear el sentido de dependencia y propiciar el deslumbramiento por la sociedad norteamericana, su historia y sus instituciones civiles y educativas. Por otra parte, aunque el Superintendente General de Escuelas en Cuba, Alexis E. Frye, en la dedicatoria a los educadores cubanos de su texto Manual para maestros ${ }^{11}$ reclamó "libertad absoluta para el maestro", la política educacional en la enseñanza primaria transitó progresivamente hacia el centralismo y la burocracia con los que frustraron los impulsos creativos de los docentes.

\footnotetext{
9 Ver: Junta de Educación del Distrito Urbano de La Habana, Contrato con maestros, a nombre de Dulce María Borrero, de la Escuela No. 38, aula No. 1, firmado el 31 de agosto de 1902. Fondo Los Borrero, ILL (BOR-D, No. 563). Estaba vigente entonces el Manual o Guía para los exámenes de los maestros cubanos, conforme al programa oficial acordado por la Junta de Superintendentes de Escuelas Públicas de la Isla de Cuba, Imprenta, Librería y Papelería La Moderna Poesía, La Habana, 1902, 3t.

10 Ver: Ministerio de Educación, La educación en los cien años de lucha (La Habana: Editorial Pueblo y Educación, 1968 ), 11.

11 En la dedicatoria, Frye desea que desde su libro se valide siempre un lema: "libertad absoluta a todo maestro, para que emplee su propio método de enseñanza”. Ver en Ramiro Guerra, La educación primaria en el siglo XX. Proceso histórico de la misma en Estados Unidos de América, Gran Bretaña y Cuba (La Habana: Centro Superior Tecnológico, 1955), 198.
} 
En las primeras décadas del siglo irán introduciéndose en la educación cubana las influencias de Pestalozzi, Herbart y Spencer. De procedencia norteamericana, de modo parcial y limitado, se asumirán las ideas de John Dewey, propulsoras de una escuela vitalista y de nexos funcionales con su contexto. Pero, en tanto se propugnaba el pragmatismo utilitarista, la corriente ideológica de más fuerza en la escuela pública mantuvo regularmente la impronta de las expresiones autóctonas de la identidad nacional. Los libros de texto contribuyeron sustantivamente en esta última dirección. De modo particular: Nociones de Historia de Cuba, de Vidal Morales (1901); Trozos selectos en prosa y verso de autores cubanos, de Nicolás Heredia (1901); El nuevo lector cubano, de Carlos de la Torre y Huerta y Esteban Borrero Echevarría (1918); Libro Quinto de Lectura, de Ramiro Guerra Sánchez y Arturo Montori (1918). Y el de mayor trascendencia en la etapa: Historia elemental de Cuba, de Ramiro Guerra y Sánchez (1922). ${ }^{12}$

Varios educadores de la primera mitad del siglo testimonian sobre el panorama desolador del modelo educativo cubano del sistema público, tanto en potencial humano como en recursos materiales. Algunos de ellos fueron Enrique José Varona, Ramiro Guerra, Arturo Montori, Carolina Poncet, Alfredo M. Aguayo. Claman también por el mejoramiento urgente y sostenido de la educación cubana, en tanto decrece el presupuesto que se le asigna, y con frecuencia se malversan sus fondos oficiales. Ramiro Guerra, el educador y superintendente provincial (1913-1915) que llegó a ser un renombrado historiador, describió la declinación de la enseñanza primaria, cuyas primeras evidencias advirtió entre 1907 y 1912. Para entonces ya ha tenido lugar la aplicación de la desacertada Ley Escolar del 8 de junio de 1909 que politizó el acceso a las plazas educativas, en tanto coartó la libertad de los maestros en grado sumo con la puesta en vigor de cargas burocráticas, lo que no cambiará en décadas posteriores, por el contrario se agudizará integralmente al punto de que se hable con regularidad de "crisis escolar". ${ }^{13}$ Ante tal situación, en 1916 se creó la Sociedad Cubana de Estudios Pedagógicos "con el objetivo de reunir a educadores e intelectuales de prestigio preocupados por la evolución del sistema escolar cubano" ${ }^{\prime 14}$.

12 Ver: Perla A. Cartaya Cotta y José A. Joanes Pando, Raíces de la escuela primaria pública cubana. 1902-1925 (La Habana: Editorial Pueblo y Educación), 38-52.

13 Ramiro Guerra, "La educación primaria en el siglo XX. Proceso histórico de la misma en Estados Unidos de América, Gran Bretaña y Cuba”, en Obras Completas, ed. Darío Rubén (1955), 157-158, 177-178. Estos criterios fueron abordados por este autor y otras personalidades educativas como Enrique José Varona, Alfredo Aguayo y Arturo Montori en una obra del año anterior. Se trata de Ramiro Guerra. Rehabilitación de la escuela pública. Un problema vital de Cuba en 1954 (La Habana: P. Fernández y Cía, 1954).

14 Quizá Ricardo Moreno, “Cuba: historia, escuela, nacionalismo (1902-1930)”, Debates americanos, No. 5-6, enero-dic, (1998): 76-89. 
Con ahondamiento particular sobre la situación de este sistema de enseñanza primaria, la estudiosa cubana Perla Cartaya ${ }^{15}$ puntualiza la moderada etapa de bonanza que correspondió al desempeño de la vicepresidencia de la República, a cargo del destacado intelectual e ideólogo Enrique José Varona (1913-1917), al crear nuevas escuelas, incrementar el presupuesto educativo y promover medidas sustanciales para incidir sobre la calidad de la enseñanza. Esto durará poco. La precariedad era el signo dominante de la enseñanza primaria, con algunos altibajos $(1914,1925)$ : escuelas insuficientes en número y en la disponibilidad de recursos, manifiestas irregularidades en el cumplimiento de la reglamentación escolar y la implantación de una disciplina que confería una autoridad excesiva al maestro. Con relación a lo último, ha de señalarse, sin embargo, que en el magisterio radicaba el principal valor de la escuela pública. En su mayoría los maestros cimentaron su ideario pedagógico en los valores éticos y patrióticos heredados de la lucha de liberación nacional con el propósito de formar ciudadanos útiles a su país, así como en la asunción de prácticas pedagógicas validadas en otros países, que aspiraban a desarrollar al educando en sus propias aptitudes y actividad. La puesta en práctica de la asignatura Moral y Cívica o de la llamada instrucción moral y cívica, junto con diversas actividades y actos colectivos encaminados al desarrollo del sentido ético del deber para la vida (en la escuela, la comunidad y el país), de sentimientos patrióticos y de enaltecimiento de valores ciudadanos, cultivados por diferentes mecanismos y disciplinas escolares, sin excluir mitificaciones, llegaron a ser pivotes de la escuela pública a la vez que contribuyeron a la progresiva articulación del discurso de la nación y la identidad nacional y cultural.

Desde la intelectualidad comprometida con la educación, Dulce María Borrero irá marcando reiteradamente este estado deplorable del modelo educativo y se pronunciará por encontrar caminos para resolverlo en cada una de las etapas en las que se detendrá este artículo. En las dos primeras décadas del siglo, además de la docencia directa ya señalada y de la dirección de escuelas en la comunidad de Puentes Grandes en La Habana, se convertirá en auxiliar de grandes maestros como Carlos de la Torre y dirigirá la Revista de Instrucción Pública en 1917 y 1918. ${ }^{16}$ En la década siguiente profundizará de forma sustantiva sus posiciones sobre el proceso socioeducativo desde las páginas de esta Revista. Más tarde seguirá las rutas asumidas.

15 Ver: Cartaya y Joanes "Raíces de la escuela", 14-57 y 59.

16 Ver: Darío, Rubén, “Obras Completas”, 174. 


\section{Años prolíficos: $1920-1939$}

Los años veinte en Cuba constituyeron un espacio temporal en el que se fortaleció la conciencia nacional y antiimperialista, a la vez que se cuestionaba el poder político. Tuvieron lugar numerosos acontecimientos políticos, económicos y socioculturales, muchos de los cuales fueron protagonizados por luchas obreras, campesinas, estudiantiles, intelectuales y de la mujer, cuestionadoras de la situación imperante en el país de corrupción y entreguismo a la politiquería y a los capitales foráneos. Entre estos acontecimientos ocupan un lugar importante la llamada Protesta de los Trece $^{17}$ (la asonada de la joven intelectualidad de 1923 frente a la corrupción gubernamental) y los dos primeros congresos nacionales de mujeres, los de 1923 y 1925, en los que tuvo papel destacado Dulce María Borrero. Desde 1914 y 1918 ella había dado a conocer sus posiciones condenatorias de las concepciones patriarcales sobre el matrimonio y los prejuicios en torno al divorcio. ${ }^{18}$ Pero será a partir de 1923 cuando fructifiquen intensamente estas proyecciones. Sus afanes por la emancipación de la mujer la condujeron a ser testigo comprometido de la citada Protesta de los Trece; a participar de modo significativo en los congresos nacionales de mujeres a través de la defensa de los derechos femeninos y de la niñez; ${ }^{19}$ a divulgar los intereses pedagógicos a favor de la escuela pública, preservadora de los valores de la nación y a promover la cultura popular.

Cuando irrumpe esta década, a la altura de 1920, uno de los educadores que mejor domina el entorno del sistema educativo cubano es Ramiro Guerra. De larga experiencia docente en distintos niveles de responsabilidades, como profesor de la Escuela Normal de Maestros, critica la situación de la enseñanza pública en la cual, según sus propias palabras, se comete un "crimen colectivo" contra la infancia desde el propio inicio del curso escolar: los niños o no tienen escuelas o se hacinarán en locales sin condiciones para la educación por su falta de ventilación y luz, por su suciedad, humedad o pestilencia. Denuncia que:

Hay aulas en los zaguanes, en las cocinas, en viejos cuartos reducidos y sombríos como una prisión (...). Setenta, ochenta, cien niños, se aglomeran

\footnotetext{
17 Ver Yolanda Ricardo, "Nueva visión", 50-64.

18 Dulce María Borrero, "El matrimonio en Cuba", Cuba Contemporánea. No.2, año II, (1914): 198-211 y el Discurso en la sesión pública inaugural del Club Femenino de Cuba (3 de julio de 1918) (La Habana: Rambla Bouza y Cía, 1918).

19 Ver Yolanda Ricardo, "Nueva visión", 36 y 64-91.
} 
en espacios donde estrechamente cabrian diez o quince. Las pizarras están colocadas a veces detrás de las puertas, fuera de la vista de los escolares. No hay patios, y los niños han de permanecer sentados o de pie oprimidos unos contra otros, inmóviles, respirando horas y horas el aire confinado de las aulas, que sofoca sus débiles pulmones y envenena sus tejidos tiernos e inconsistentes. ${ }^{20}$

Al año siguiente, en una conferencia ofrecida en la Sociedad Económica de Amigos de País en la capital, el 15 de mayo de 1921, Guerra ofrece una visión global sobre la enseñanza primaria de la etapa en un artículo valorativo publicado en la revista Cuba Contemporánea, la de más peso sociocultural del momento: "La enseñanza no es solo poco intensa en cuanto al conjunto de conocimientos que se transmite a los niños: adolece también del defecto de someter a una disciplina inadecuada las facultades del discípulo, dejando inactivos sus poderes de observación personal, de reflexión y de iniciativa". ${ }^{21}$

Dos problemas de primera magnitud crecen por estos años: el desprestigio del sector magisterial y la baja asistencia del alumnado a las insuficientes escuelas disponibles. Los maestros asociados exigen que se realice la reforma en las Escuelas Normales -creadas en 1916-, puesto que sus egresados no poseían las condiciones idóneas para el ejercicio de la profesión, ni en preparación ni en valores morales, sobre lo que se pronunció firmemente Dulce María en $1925^{22}$. En cuanto a los alumnos, más del 50\% de la población infantil en edad escolar no asistía a los centros educacionales ${ }^{23}$ y veía perder sus oportunidades porque no podía acceder a las escuelas por la explotación laboral o por ser víctima de mecanismos corruptos, de prostitución y juego. En los medios rurales la situación era mucho más grave.

En estos contextos de las primeras décadas de la República, en los que la educación cubana muestra diversidad de problemas, la teorización pedagógica que desde la prensa especializada realiza Dulce María es notablemente prolífica, funcional y comprometida. En 1925, en la Revista de Instrucción Pública, de la que fue redactora de 1926 a 1928, aparecen sus textos “Misión

20 Ramiro Guerra, “Camino de la escuela”, Revista Educación, No. 95, sept-dic. (1998), 49-51. En el artículo se añade que se trata de un fragmento del texto "Los problemas del niño", aparecido el 21 de septiembre de 1920 en el Diario de la Marina.

21 Ramiro Guerra. "El estado actual de la enseñanza primaria en Cuba", en Cuba Contemporánea Tomo XXVII, No. 106, octubre, año IX, (1921): 89-105.

22 Dulce María Borrero, “Instrucción complementaria del maestro. Las Escuelas Normales de verano", Revista de Instrucción Pública, año I, No.3, diciembre, (1925):130-141.

23 Cartaya y Joanes, "Raíces de la escuela", 55; refiriéndose al texto de Fernando Ortiz, La decadencia republicana. Datos métricos del retroceso de Cuba (Ciudad: Editorial, 1921). 
suprema y supremo deber del maestro" y el ya citado "Instrucción complementaria del maestro. Las Escuelas Normales de verano". En la propia Revista, en 1926 se publican: "La vida del niño campesino de Cuba", "Viajes de instrucción a los maestros", "La ornamentación de la escuela”, "La cooperación de los maestros y los padres de familia" y "La vocación y la escuela". En las páginas de este órgano se manifiesta su admiración por el ideario de Pestalozzi, a quien dedica el poema "Gesta fecunda. A Pestalozzi", en el número confeccionado sobre su obra pedagógica en $1928 .{ }^{24}$ De estos trabajos sobresale, por su verticalidad frente a los elementos políticos y socioculturales que influían negativamente en el proceso socioeducativo, el titulado "Misión suprema y supremo deber del maestro". ${ }^{25}$ No se trata de explicar el declive de la escuela pública en sí misma, sino en las causas que lo provocan. Son tiempos en los que la intelectualidad cubana progresista y revolucionaria se pronuncia sobre la evidente decadencia de la sociedad cubana como expresión de los sucios manejos de los poderes públicos, de la manipulación política de las plazas en la educación. Y los maestros, según este texto, se manifiestan desencantados, escépticos, desilusionados. Necesitan estímulos, respaldo para su superación, garantía de empleo.

El tema de la situación sociocultural del niño campesino -sin oportunidades de ocio y juego, con un trabajo corporal y obligaciones domésticas por encima de su desarrollo fisiológico y mental- que aborda en el artículo citado de 1926 pudiera ser el sedimento de sus Apuntes sobre la escuela rural. ${ }^{26} \mathrm{Si}$ se toma en cuenta que su amiga Petrona Noda, educadora también, en carta ${ }^{27}$ de inicios de ese año le sugiere que escriba sobre este tipo de institución escolar y su situación deprimente en el país, cabría pensar que el artículo en ciernes pertenece a los años finales de la década del veinte o a inicios de la siguiente. En un texto posterior, "La educación de los hijos", conferencia del 27 de agosto de 1934, vuelve al tema sobre el carácter "sombrío" de la vida del niño campesino y exhorta a las llamadas "Señoritas Agricultura", especie de promotoras de conocimientos dirigidos al agricultor, a que divulguen entre las familias campesinas no solo elementos científicos de los cultivos, sino también prácticas saludables y estimulantes espirituales para la familia y el niño, sin desconocer la cruda realidad de la vida del campo. Demanda

24 Revista de Instrucción Pública, año III, No. 2, febrero, (1927): 178-180.

25 Dulce María Borrero. "Misión suprema y supremo deber del maestro", en Revista de Instrucción Pública, La Habana, año I, No.2, noviembre, (1925): 57-65.

26 Fondo Los Borrero ILL BOR-D 410.

27 Carta de inicios de 1926. Los Borrero ILL, Caja 6, No. 326. 
que se multipliquen y extiendan hasta los más recónditos parajes las escuelas rurales. Con todo esto, Dulce María asume un problema que se encuentra en el vórtice de las demandas educativas: la creación y sostén de escuelas rurales, pocas en cantidad, pobres en todos los sentidos, e inexistentes en las regiones aisladas o intrincadas. En 1935, se concretará y cohesionará en el país, particularmente en la capital, un movimiento "pro escuelas rurales", impulsado por fuerzas de izquierda. ${ }^{28}$ Los educadores más progresistas se pronunciarán en sentido similar. Dulce María, entre ellos.

Para entonces, la educación cubana ya venía buscando vientos renovadores que tienen sus raíces en el siglo anterior. La segunda mitad de la centuria decimonónica había traído consigo, junto al fenómeno imperialista estadounidense, una significativa complejidad en los procesos tecnológicos y el creciente carácter socializado del proceso productivo. Consecuentemente con esa estructura económica, emergieron representaciones ideológicas positivismo, pragmatismo- que desde la educación ofrecieron respuesta funcional a las nuevas demandas con las llamadas escuelas activas, antecedentes de la escuela nueva.

Irradiando desde Europa Occidental, en varios de los países técnicamente desarrollados se implantaron los métodos de la escuela nueva al punto de llegar a crearse un Buró Internacional de Escuelas Nuevas. ${ }^{29}$ Se expandieron las teorías de Decroly, Montessori, Piaget... Se propugnó el activismo del niño como sujeto del aprendizaje y de la educación al servicio de la vida. En Cuba estas ideas consideradas modernizadoras encontraron un clima favorable en la cuarta década del siglo XX, porque tanto los pedagogos de más luces como algunas instituciones educacionales pretendían reformar un sistema de enseñanza al que se le señalaban lastres, tales como la desvinculación del alumno con la vida, su falta de autonomía en el aprendizaje y el insuficiente desarrollo de su personalidad. Si bien el movimiento de la escuela nueva fue asumido en una primera fase apenas sin cuestionamientos, más tarde pedagogos de importancia como Alfredo Aguayo (Didáctica de la Escuela Nueva, 1932) y Diego González (Didáctica o dirección del aprendizaje, 1946) atemperaron sus principios y métodos a la contextualización de la educación y la tradición cubanas, con énfasis en el aspecto axiológico de la formación del educando. ${ }^{30}$

28 Justo A. Chávez Rodríguez, Bosquejo histórico de las ideas educativas en Cuba (La Habana: Editorial Pueblo y Educación, 1996$), 95$.

29 Lorenzo Luzuriaga, Diccionario de pedagogía (Buenos Aires: Editorial Losada S.A, 1966), 138-139.

30 Ver: Chávez Rodríguez, "Bosquejo histórico...”, 93-94. 
Del primer momento, del entusiasmo transformador que caracterizaba el vitalismo de la Escuela Nueva, es el texto titulado Nuevo sentido de la misión del maestro en la Escuela Renovada, que preparó Dulce María Borrero para presentarlo a modo de conferencia en el "Curso Los amigos de la escuela nueva", del Colegio Presbiteriano Carlos de la Torre, de Sancti Spíritus, el 24 de octubre de 1936. Se reafirma la educadora que está atenta a cambios e innovaciones que puedan favorecer la labor formadora desde el ámbito escolar. Sobre sus ideas expuestas en esta oportunidad volverá en su disertación Educación pacifista del niño, de 1939.

Un tema que se encabalga entre los años treinta y cuarenta es el de la paz. En 1938 publica su conferencia La mujer como factor de la paz en la que contextualiza la urgencia de la solidaridad con la España Republicana "que está siendo desgarrada" ${ }^{31}$ y se vuelca también hacia su relación con la niñez, asunto de marcada actualidad por los acontecimientos bélicos que conmocionaban Europa y Asia y por su valor educativo. Es por eso que es invitada en la Fiesta Intelectual de la Mujer (La Habana, febrero de 1939) para que diserte sobre estos temas y sus nexos socioeducativos y axiológicos. En su conferencia ya mencionada, Educación pacifista del niño, una idea preside sus juicios más destacados: cuando se siembra paz, se cosecha cultura y ha de sembrarse la conciencia de la paz desde las edades tempranas, la familia y la escuela.

\section{Sus últimos cinco años}

Su notable proyección humanista y la paz, como elemento temático recurrente ante los acontecimientos bélicos en Europa y el ascenso agresivo del nacionalsocialismo, están presentes en sus escritos de los años finales de la década del treinta hasta su fallecimiento en 1945. Así lo testimonia su participación en campañas por el auxilio a los niños españoles separados de sus padres y patrias por el fascismo y por repatriar a los cubanos que se enfrentaron al franquismo y a la alianza nazi-fascista como parte de las Brigadas Internacionales en la Guerra Civil Española. Pero también textos como Mi homenaje a la madre: no el cántico, la paz, conferencia pronunciada en la Logia Luisa Pérez de Zambrana, el 12 de mayo de 1940; y “Libertad: fundamento y esencia de la vida", artículo de julio de 1943.

31 Dulce María Borrero, La mujer como factor de la paz (La Habana: Tipografía Modelo, 1938), 6. 
En los ámbitos universitarios, el 25 de febrero de 1942 pronunció un discurso en la Facultad de Educación de la Universidad de La Habana en el que, además de enlazar valores educativos con la defensa del acervo patrimonial de la cultura cubana, reclama acciones firmes para enfrentar las consecuencias de la Segunda Guerra Mundial, tanto en lo que significa "la absorción física de las naciones" por parte de los agresores como "el aniquilamiento espiritual de cada una de ellas". 32 Paralelamente, su pluralidad intelectual y educativa recibe constantemente reconocimientos y galardones de parte de instituciones culturales y educacionales. La nombran Presidenta de Honor de la Asociación Nacional Femenina de Prensa. Diserta varias veces en la Academia Nacional de Artes y Letras. Una especie de coronación de su proyección magisterial, que ha venido desarrollando desde la década anterior con el impulso a la creación de las bibliotecas populares, la retoma junto con la difusión del libro como vía de desarrollo sociocultural, en sus trabajos de dirección en la Asociación Bibliográfica Cultural Cubana, fundada por ella en 1937.

\section{Pensamiento pedagógico}

Como en el corpus de este texto se enfatizó en el peso de las teorizaciones sobre la educación de la pluma de Dulce María, puede ser útil agruparlas tematizándolas a partir de una selección de juicios ilustrativos de sus posiciones.

\section{La proyección social de la educación}

En este aspecto habría que plantear los criterios de Dulce María Borrero en dos sentidos: uno, en el papel del maestro y de la educación dentro de la sociedad; y otro, en el carácter de la escuela, conforme a los requerimientos socioculturales de un contexto histórico determinado. Sobre lo primero, Dulce María entronca su posición con la del educador decimonónico José de la Luz y Caballero, uno de los padres fundadores de la nacionalidad cubana y paradigma educativo, en tanto que los dos absolutizan la labor docente al asumirla como fuerza hegemónica de las transformaciones sociales. Para José de la Luz y Caballero el maestro es el factor fundamental en la lucha

32 Dulce María Borrero, Discurso pronunciado en la Facultad de Educación de la Universidad de La Habana. Archivo de la Familia Borrero Pierra. Ver Yolanda Ricardo, "Nueva visión", 33-35. 
contra la colonia: “Tengamos el magisterio y Cuba será nuestra" ${ }^{33}$ Del mismo modo, manifiesta Dulce María Borrero en 1936, en la inauguración de una biblioteca pública en homenaje a José Martí, que “...el único remedio a nuestros males está en la elevación progresiva de la mentalidad de las masas, en el pulimento del espíritu y la afirmación singular del carácter del cubano..." ${ }^{34}$ Y en otro momento, también en 1936 en la región central del país, en Sancti Spíritus, puntualiza: “...únicamente por la actuación elevada del maestro podrá obrarse el milagro de una transformación medular en nuestra vida desorganizada y deshecha". ${ }^{35}$ Entiende, además, que la escuela es una institución en la que debe articularse la acción de las diversas fuerzas sociales, básicamente la interacción de los educadores y la familia.

Desarrolla estos puntos de vista en su artículo de 1926 titulado La cooperación de los maestros y los padres de familia, en el cual subraya el apremio de crear mecanismos respaldados por las familias de los escolares que permitan extender los beneficios de la educación a través de la creación de bibliotecas, del fomento de estudios complementarios, del estímulo a la siembra en huertos y jardines escolares, de la realización de actividades de promoción de sentimientos colectivos, patrióticos y de solidaridad humana.

Cuando reflexiona sobre cómo debe ser la escuela de acuerdo con las exigencias sociales, emerge su calado de raíces martianas:

Puesto que a vivir viene el hombre -dice José Martí, el pensador y líder revolucionario cubano-, la educación ha de prepararlo para vivir. En la escuela se ha de aprender el manejo de las fuerzas con que en la vida se ha de luchar. Escuelas no debería decirse, sino talleres y la pluma debía manejarse por la tarde en las escuelas, pero por la mañana, la azada. ${ }^{36}$

La escuela ha de abrirse "con amplitud y ruido de taller, con calor de fábrica, con estremecimiento creador", ${ }^{37}$ expresa Dulce María Borrero en La vocación y la escuela, de 1926. Asimismo, insistiendo en el vínculo escuela-vida y partiendo de las premisas trabajo, deporte y arte plantea en este mismo texto una manera de proceder:

33 José de la Luz y Caballero, Aforismos (La Habana: Editorial de la Universidad de La Habana, 1962 ), 368.

34 Dulce María Borrero, “Discurso pronunciado en la inauguración de la Biblioteca Pública José Martí”, Remedios, (Imprenta Antigua de Valdepares, 1936), 17.

35 Dulce María Borrero, (1936) Nuevo sentido de la misión del maestro en la Escuela Renovada Manuscrito. Fondo Los Borrero ILL, BOR-D 410.

36 José Martí, “Peter Cooper”. en Obras Completas, tomo 13 (La Habana: Editorial Nacional de Cuba, 1964 ), 53.

37 Dulce María Borrero, “La vocación y la escuela”, en Revista de Instrucción Pública, año II, No. 9, noviembre, (1926): 867. 
...despertar, nutrir y desarrollar en el pueblo la capacidad creadora, abriendo al instinto infantil vías propicias en la dura represa de la instrucción oficial, demasiado pesada, demasiado complicada, demasiado ampulosa quizás, pero en el fondo insuficiente a nuestra necesidad inmediata, que es la de hacernos una conciencia y un brazo, una personalidad propia, en fin, que nos distinga y que nos valga al mismo tiempo. ${ }^{38}$

\title{
6. El maestro
}

Durante la ocupación norteamericana en Cuba de inicios del siglo XX, los maestros pertenecían en gran medida a familias ilustradas, muchas procedentes de los emigrados revolucionarios que regresaban tras el fin de la guerra en 1898. Luego, el Ejército Libertador desmovilizado nutrió de modo sensible las filas del magisterio y le inyectó calor popular y aliento emancipador. Esto fortaleció entre los maestros el sentimiento de pertenencia y de identidad: un valladar que se construía desde la escuela pública ante la penetración imperial. Dulce María, como parte de esos primeros educadores de la República naciente, se refiere particularmente a los maestros decimonónicos que impregnaron su impronta en la forja de la conciencia como pueblo, como los grandes maestros fundadores de la nación cubana, fuentes de los noveles. En su artículo Misión suprema y supremo deber del maestro destaca que:

\begin{abstract}
Cuando en la heroica gesta de su independencia Cuba necesitó estímulos morales para plasmar una conciencia vigorosa, concordante en un todo a su ideal, maestros fueron los que dieron al pueblo la sustancia nutricia de sus primeras definiciones patrióticas, maestros los que marcaron con el ejemplo vivo de sus actos, sus orientaciones iniciales en la erizada senda del deber. ${ }^{39}$
\end{abstract}

Desde estas coordenadas presenta un concepto altamente enaltecedor de la función social del maestro. Es el animador de conciencias, el "que educa", el "que guía", el "que despierta", el que marca derroteros a imitar por la juventud, el que ha sido designado por la sociedad para cumplir la misión más alta a la que puede ser llamada una persona, porque su misión es la de formar hombres. Nuevamente con savia martiana le confiere al educador el carácter de creador, a la vez que destaca la devoción que el maestro ha de sentir por su trabajo con la entrega de sí mismo. Una década más

38 Borrero, "La vocación", 868-869.

39 Borrero, "Misión suprema", 58. 
tarde, en 1935, en El magisterio y el porvenir de Cuba le otorga al educador un papel cimero en la preservación de la identidad nacional y cultural cuando lo coloca en función de devolver "su imagen al cubano". En este sentido se pronuncia a modo de sentencia cuando afirma:

...si el maestro, en vez de unir al hombre con su tierra como en un solo bloque, lo infiltra de ideas despreciativas de lo suyo, lo mixtifica con ajenos deseos y lo deprava con el fermento de la ingratitud, su obra no solo no inspirará ya respeto, sino se hará merecedora del anatema de quienes queremos salvar por encima de todo a Cuba con su pueblo. ${ }^{40}$

\section{La formación y superación de los maestros}

Consciente de la función orientadora del educador, exige de él un espíritu de superación, mantenido a través de las llamadas "horas post escolares" bajo la forma de instrucción complementaria. Para que se renueve espiritual e intelectualmente y mantenga siempre dentro de sí el impulso del estudio, de la curiosidad, del conocimiento creciente, en su artículo de 1925 titulado Instrucción complementaria del maestro. Las Escuelas Normales de verano identifica varias fórmulas, entre ellas: las escuelas normales de verano, el cultivo sistemático de la lectura, el cambio de objetivos en los viajes de instrucción de aquella etapa. En la puesta en práctica de la superación durante el verano identifica procedimientos que garantizan la sistematicidad del intercambio de experiencias entre los educadores, el conocimiento de su medio educacional y la consiguiente aplicación de la ciencia pedagógica. Y por último, afirma que la emulación que genera este tipo de encuentro periódico entre educadores contribuye a infiltrar nuevo entusiasmo en el desempeño del deber, en el reconocimiento de su autoridad profesional y humana.

Recomienda al maestro dos tipos de lectura como recurso indispensable para incrementar su perfeccionamiento académico y moral: la lectura colectiva propiciadora de la discusión y del crecimiento de una cultura integral, y la individual que enriquece la visión universal. Más tarde, en 1936, sostendrá que "una obra de Shakespeare tiene, por su unidad de belleza y la fuerza cardinal de su asunto, un poder edificador quizás mayor que el de otras muchas obras de tendencia filosófica pura" ${ }^{41}$ Por otra parte, cuando hace el recuento

40 Dulce María Borrero, Dos discursos. El magisterio y el porvenir de Cuba. La Fiesta Intelectual de la mujer: su actual significado; su misión ulterior (La Habana: Cultural S.A, 1935), 10, 15-16.

41 Borrero, "Nuevo sentido", 410. 
del resultado obtenido en los viajes a otras naciones destinados a la instrucción de los maestros ${ }^{42}$ expresa que estos serían más provechosos si dejaran de ser rápidas ojeadas a parques, monumentos, museos y bibliotecas, y se convirtieran en un conocimiento del desarrollo de esos países y en la visita a clases de profesores destacados.

\section{La educación artística en la escuela}

Fiel a su reiterada posición de defensa de la identidad nacional, se propuso dotar al nivel de enseñanza pre-escolar, el entonces Kindergarten, de las canciones adecuadas para la actividad formativa de la infancia en esa etapa, como se transparenta en sus palabras introductorias al libro Cantos escolares, de 1925. Consideraba que los cantos norteamericanos orientados para ese fin “...carecían (...) de valor positivo como factores de educación para [los cubanos], ya que hablaban a nuestros niños de asuntos y costumbres desusados en nuestro medio". Señala la ausencia total en ellos de "... nuestros grandes hechos históricos (...), de nuestros héroes inmortales". 43 Sigue manifestando, al referirse a la labor creadora de los trabajadores de la enseñanza del primer nivel escolar:

No debe contentarse el maestro, forjador de espíritus fuertes y conciencias serenas, con tener a su alcance en ese momento delicadísimo en que los niños no han dejado aún por completo el calor del regazo maternal, el caudal de aquellos instrumentos que sirvan solo para fijar en su cerebro el fundamento de los conocimientos puramente objetivos, sino que debe aprovechar también todos aquellos de apariencia más compleja o abstracta, pero que de algún modo contribuyan a suscitar en él aquellas nociones morales y estéticas que determinen y fijen su afición ulterior por lo bello y lo noble de la vida. ${ }^{44}$

Tan elevados como funcionales propósitos animan las cuarenta y cinco canciones escolares escritas por Dulce María para el libro citado anteriormente, con música de Fidelma García: un rico venero para la formación de los niños cubanos en su estreno en la vida escolar en la primera mitad del siglo XX. Además de constituir la sedimentación incipiente para la fase instructiva inicial, estas canciones se proyectan como himnos a la vida, al trabajo, a los

\footnotetext{
42 Ver: Dulce María Borrero, “Viajes de instrucción a los maestros”, Revista de Instrucción Pública, año II, No. 1, febrero, (1926): 139-148.

43 Dulce María Borrero, “Prefacio”, en Cantos escolares., eds. Bouza y Cía (La Habana: Imprenta Rambla, 1925$), 5$.

44 Borrero, "Prefacio", 9.
} 
valores patrióticos, en circunstancias en las que se reevaluaba el verdadero sentido de la independencia y de los atributos nacionales. Algunas de ellas han sido incorporadas con algunas variaciones, sin el texto musical, a los libros para el aprendizaje de la lengua materna en el sistema de enseñanza cubano desde 1976. Las que primero se publicaron en el cuerpo de los textos escolares fueron: A la escuela, en Lectura 1 (Editorial MINED, 1976); A las aulas, Las aves y La siembra, en Lectura 2 (Editorial MINED, 1976); La zafra, en Lectura 3, (Editorial MINED, 1977). Otras composiciones de la autora, no pertenecientes al libro Cantos escolares, igualmente sirvieron de texto en las escuelas primarias de la segunda mitad del siglo XX, durante la etapa revolucionaria posterior a 1959. Lo mismo sucede hoy día con los poemas Mi bandera" (en Lectura 1, Editorial Pueblo y Educación 1988, 2010, 2011, 2012); La bandera cubana (en Lectura 4, Editorial Pueblo y Educación 1991, 1992, 1997) y La mentira (en Lectura 3, Editorial Pueblo y Educación 1990, 2002, 2004, 2008). En Lectura 2, de segundo grado, aparecieron Mi bandera, Las aves y La siembra (Editorial Pueblo y Educación 1989, 1991, 2010).

Partiendo de la opinión de que la belleza es para el disfrute de todos y no hay "placer de ricos y de desocupados", en su artículo La vocación y la escuela analiza las escasas posibilidades de las instituciones escolares de su tiempo destinadas, según su visión, a trillar el camino de la sensibilización artística de los alumnos y a la búsqueda de los temperamentos que atesoran aptitudes creadoras en el campo del arte. Valora entonces que:

Entre la población juvenil de ambos sexos que abandona las aulas de la escuela primaria y reingresa en la masa popular (...) ; cuántos artífices han dejado de formarse, hábiles y diestros, cuánto factor efectivo de progreso ha sido inutilizado; cuánta gloriosa personalidad ha sido matada antes de nacer! De la inteligente muchedumbre de jóvenes hijos del pueblo que llena actualmente las aulas de la República, ¿cuántos se levantarán mañana a cantar sus hazañas gloriosas, a esculpir en el mármol sus bellezas, a fijar en el lienzo, con conciencia viril, su verdadera fisonomía? ¿Saldrá de las escuelas de hoy ese ejército poderoso de trabajadores y de artistas que es el único ejército capaz de salvar de la muerte a las naciones?... ${ }^{45}$

Imbricando las finalidades instructivas con la ética y la estética, en La ornamentación de la escuela insiste en las diferentes maneras que puede utilizar la

45 Borrero, "La vocación y la escuela", 866-867. 
educación primaria para hacer atractiva e interesante cada una de locaciones en donde tiene lugar el trabajo educativo. Así también destaca el valor vivencial del ejemplo cuando expresa:

No basta hablar a los niños de orden, de higiene, de compostura y decoro personal, de pulcritud en el vestir y de deberes recíprocos en la vida (...) vale más hacerles sentir el penetrante efecto de estas enseñanzas esenciales, rodeándolos de las ventajas incomparables de una realidad cuyo valor demostrativo jamás resulta estéril. ${ }^{46}$

\section{La escuela rural}

Como se afirmó anteriormente, la escuela enclavada en el campo fue objeto de preocupaciones por parte de las fuerzas de avanzada política y social en la primera mitad del siglo XX en Cuba. El 5 de mayo de 1921 Ramiro Guerra reclama la atención sobre estas instituciones escolares para que puedan preparar eficazmente al campesino y estén en capacidad de enfrentar la pobreza no con "el billete de lotería" o la valla de gallos. Declara que la población rural es la que padece mayor desamparo por parte del Estado y la que cuenta con "menos posibilidades de educarse y progresar". ${ }^{47}$ Para Dulce María Borrero, seguramente informada del debate público en torno al tema, ${ }^{48}$ y contando con sus propias experiencias de sus visitas a la entonces provincia de Camagüey y a Calimete, antigua provincia de Matanzas, en donde vivía la educadora Petrona Noda, esta realidad es razón de deber y acicate para pronunciarse en torno a ella.

En sus Apuntes sobre la escuela rural subrayó el hecho de que esta era la única fuente por la que los campesinos de su tiempo podían tener acceso a la educación y a la cultura y por ello reclamaba del maestro su devoción mejor para atenderla. Al mismo tiempo, apuntó que con esta institución escolar se podía rescatar al niño campesino de la anulación a que lo sometía el trabajo prematuro realizado como auxilio a sus padres en las faenas agrícolas, causa importante del deterioro físico de la niñez rural y de las ausencias a clases de los escolares en esas zonas. En sus reflexiones sobre este tema seña-

46 Ver: Dulce María Borrero, “La ornamentación de la escuela”, Revista de Instrucción Pública, año II, No. 3, marzo, (1926): $238-244$.

47 Ramiro Guerra, "El estado actual de la enseñanza primaria en Cuba", en Cuba Contemporánea, Año IX, No. 106, tomo XXVII, octubre (1921): 89-105.

48 Desde mucho antes de la fecha referida en la carta de Petrona Noda (1926), el tema de la escuela rural preocupaba a la intelectualidad cubana, medio en el que desplegaba su acción socioeducativa y cultural Dulce María Borrero. Poco después, en 1931, un maestro de experiencia en este tipo de enseñanza, Felipe Correoso del Risco, publicó un estudio significativo sobre esta institución escolar tan preterida. El libro de Correoso del Risco fue divulgado en la prensa capitalina y respaldado académicamente por uno de los pedagogos de más renombre y, además, conocido de Dulce María: Alfredo Aguayo. 
ló tres fuentes para la educación en el campo: la naturaleza, proveedora de motivaciones; el trabajo, fuente de vivencias estimulantes que avivan la seguridad y los poderes creadores del niño; y la experiencia alcanzada durante las labores escolares realizadas de modo grupal con la participación de los llamados equipos, motivadores del sentimiento de la solidaridad y del "mejoramiento colectivo".

\section{La Escuela Nueva}

En su conferencia ya citada de 1936 Nuevo sentido de la misión del maestro en la Escuela Renovada, Dulce María consideró, conjuntamente con otros renombrados teóricos de la educación cubana, que la escuela nueva era una reacción positiva contra el "rutinarismo" (consustanciado a la metodología pedagógica tradicional) y contra la sobrecarga de contenidos en los programas de estudio. Calibró muy positivamente los métodos del nuevo movimiento por su carácter estimulante de las capacidades integrales de los educandos y por constituir resortes propiciadores del desarrollo a plenitud de su personalidad en dos grandes vertientes, la anímica y la fisiológica, todo lo cual, desde su punto de vista, se convierte en necesidad priorizada en la infancia. Corona este criterio al opinar que, como todo en el niño transita por la expresión y el movimiento, es precisamente por esos mismos medios que ha de buscarse y mantenerse su atención. De aquí que califique este movimiento de muy favorable para la educación, porque basa en "la libertad y autodeterminación del educando su premisa científica suprema". ${ }^{49}$ En su valoración global manifiesta que la escuela nueva representaba una expresión de la urgencia de reforma de "la escuela descuidada de la República", aunque no deja de reparar en la contradicción existente entre esos empeños y el contexto adverso que ofrecía la sociedad cubana de entonces. Asevera entonces de modo categórico:

Lo salvador para Cuba (...) cuando el carácter y el alma del nativo se deforman, y los perfiles tradicionales de su figura cívica se borran, sería que los educadores todos (...) acordaran una misma actitud en cuanto a los medios a emplear para la formación del individuo normalmente capaz, y reconocieran que no hay instrumento más eficaz para lograr esta finalidad, que una disciplina creada sinceramente en lo intimo de los espiritus en formación (...) y que sintieran como una verdad imperativa

49 Dulce María Borrero, "Educación pacifista del niño", en Revista América año 1, No. 2, febrero, (1939): 38. 
en sus conciencias el deber de mantener el espíritu del escolar libre de toda presión tiránica y absurda. ${ }^{50}$

\section{Educación pacifista del niño}

En el texto que da título a esta sección, la educadora parte de la premisa de la formación del niño amante de la paz para llegar a alcanzar al "hombre antibélico del porvenir". Pero, para echar las bases de la pedagogía para la paz continúa exponiendo- se hace indispensable destruir las razones de la guerra: la "ignorancia, miseria, depauperación mental y fisiológica, injusticias, desproporción de deberes, negación de derechos, abusos de poder" ${ }^{51}$ En el caso de Cuba advierte el apremio de enfrentar la explotación y las crueldades de la marginalidad y la pobreza, senderos por donde transitan ineludiblemente los niños desvalidos hacia la delincuencia y el abandono de la escuela.

Valora también otros factores que inciden en el clima de violencia que caracteriza a la sociedad cubana de entonces. Es el caso de las imágenes guerreristas que multiplica el cine tanto en los filmes como en los carteles divulgativos y el de la proliferación de los juguetes bélicos que promueven prácticas agresivas en la niñez. ${ }^{52}$ Del mismo modo, plantea que los educadores deben incidir en el enfoque que se aplica a la enseñanza de la historia para despojar las aureolas de los próceres de sus hazañas militaristas y, por el contrario, ofrecer de manera relevante sus "virtudes de civilidad" y sus acciones revolucionarias encaminadas no a destruir sino a la defensa de los valores vitales como son la libertad y la cultura. Requiere lograr un objetivo de primera importancia: que los educadores acentúen en el ser humano las características del "creador de vida, del hombre verdadero, dueño de su destino y forjador de su felicidad" ${ }^{53}$ Concluye argumentando que el maestro, la mujer, la sociedad cubana y el Estado deben ser una sola fuerza en el enfrentamiento a la ignorancia y la miseria, así como para multiplicar las aulas regidas por la educación nueva, crear lugares de recreación infantil, fomentar el deporte, intensificar el estudio de las ciencias y las bellas artes, abolir los juegos de azar, legislar para la contención del uso de armas de fuego y la venta de juguetes bélicos. Y tomar como banderas conceptos cimeros: trabajo, ciencia, arte y paz.

50 Borrero, "Educación pacifista", 39.

51 Borrero, "Educación pacifista", 37.

52 Probablemente Dulce María no lo supo, pero Belinda Ayala, la esposa de Eugenio María de Hostos, el educador puertorriqueño, presentó una propuesta a la Liga de Naciones para prohibir los juguetes bélicos. Belinda, también cubana, tenía las mismas ideas humanistas. Ver: Juan Bosch, “Mujeres en la vida de Hostos", en Visiones de Hostos (Caracas: Biblioteca Ayacucho, 1988): 131.

53 Borrero, "Educación pacifista", 43. 


\section{CONCLUSIÓN}

Dulce María Borrero, intelectual plural, cuya voz fue escuchada en las aulas, tribunas académicas, escenarios culturales y auditorios femeninos, entregó a la cultura cubana un acervo significativo de las más diversas expresiones del quehacer cultural y socioeducativo. Sus éxitos poéticos y pictóricos traspasaron las puertas del arte versal y plástico por sí mismos y se refractaron en propósitos humanistas de la educación. Primero, recrea plásticamente narraciones de su padre dirigidas a la niñez. Luego, cuando se configura uno de los textos de los primeros años de la República, el de Carlos de la Torre y Huerta y Esteban Borrero, poemas de su autoría fueron incorporados en su composición y se mantuvieron por décadas en la formación de la niñez cubana. Así también se procederá en los libros escolares de primaria de su contexto vital y de la etapa de transformación educacional cubana contemporánea. Actualmente, en el Diccionario de Autores de la Literatura Infantil Cubana, que está en proceso editorial, de la Universidad de Ciencias Pedagógicas de la provincia cubana de Sancti Spíritus, ella aparece entre los seleccionados por sus aportes en este campo.

De igual manera, es bien conocido que la prensa especializada en temas educativos fue en su trayectoria como educadora un medio enriquecedor en la formación integral de los maestros de la instrucción primaria, a la vez que llegó a ser de forma sustantiva un nexo entre estos y la actualización pedagógica: cauce de perenne vitalidad de los ejes ético-patrióticos de la identidad, reproducidos y enaltecidos a través de la escuela. Desde estos espacios la pluma y la creatividad pedagógica de Dulce María marcaron pautas en circunstancias muy desfavorables para la educación cubana, una realidad sostenida hasta 1959 en que comenzó una revolución educacional que produjo la remoción de estructuras caducas e inequitativas.

Rebasando las fronteras tradicionales de la institución escolar, en aras de educar con alcance diverso y efectivo, su ideario propicia centralizar el interés en la educación dentro de las expresiones socioculturales, reafirmadoras de lo propio en términos de nación y del compromiso del educador con su tiempo: el maestro es un paladín de la transformación social, razón por la cual vivifica su imagen y personalidad, a la vez que le otorga especial relieve a su obra cinceladora del desarrollo pleno de la niñez; a la lucha por la 
regeneración nacional frente a la corrupción nativa; al patriotismo, sendero múltiple de la preservación de la identidad nacional; y a la defensa de la paz, un problema crucial abordado con lúcida dimensión humanista.

Dulce María Borrero sembró conocimientos y procederes pedagógicos entre los maestros coetáneos, a la vez que ejerció un valioso magisterio desde posiciones de avanzada como mujer librepensadora y como creadora en un país que se debatía entre los afanes de las fuerzas que aspiraban a construir una nación soberana y el poder oligárquico caracterizado por la corrupción y el entreguismo a los planes neocolonialistas. Si se quisiera definir sintéticamente su producción en el campo socioeducativo, podría afirmarse que en casi toda su obra es constante la orientación axiológica, porque para ella la verdad y la fe son caminos de salvación de los pueblos, a los que suma la asunción de la ética y la estética, la "eficacia de la belleza", la "belleza moral" que abre los caminos hacia la Patria, hacia la Vida, hacia la Humanidad.

\section{FUENTES}

Colección de manuscritos y otros documentos (CM Borrero), La Habana-Cuba. Fondo Los Borrero, Biblioteca Nacional José Martí.

Colección de manuscritos y otros documentos (ILL), La Habana-Cuba. Fondo Los Borrero, Biblioteca del Instituto de Literatura y Lingüística.

Archivo de la Familia Borrero Pierra, en posesión de Mercedes Borrero 1973.

Borrero, Dulce María. “El matrimonio en Cuba”, en revista Cuba Contemporánea, No. 2, (1914): 198-211.

Borrero, Dulce María. Discurso en la sesión pública inaugural del Club Femenino de Cuba. La Habana: Rambla, Rambla y Cía, 1918.

Borrero, Dulce María. "Prefacio" y textos, en Cantos escolares. La Habana: Imprenta Rambla, Bouza y Cía., 1925.

Borrero, Dulce María. "Misión suprema y supremo deber del maestro", en Revista de Instrucción Pública, No.2 (1925): 57-65.

Borrero, Dulce María. “Instrucción complementaria del maestro. Las Escuelas Normales de verano", en Revista de Instrucción Pública, año I, No. 3 (1925): 130-141.

Borrero, Dulce María. "La vida del niño campesino de Cuba", en Revista de Instrucción Pública, año II, No. 1 (1926): 48-60.

Borrero, Dulce María. “Viajes de instrucción a los maestros”, en Revista de Instrucción Pública, año II, No. 2 (1926): 139-148. 
Borrero, Dulce María. "La ornamentación de la escuela", en Revista de Instrucción Pública, año II, No. 3 (1926): 238-244.

Borrero, Dulce María. “La cooperación de los maestros y los padres de familia”, en Revista de Instrucción Pública, año II, No. 4 (1926): 301-310.

Borrero, Dulce María. “La vocación y la escuela”, en Revista de Instrucción Pública, año II, No. 9, (1926): 864-870.

Borrero, Dulce María. La educación de los hijos. La Habana: Tipos Molina y Cía, 1934.

Borrero, Dulce María. Dos discursos. El magisterio y el porvenir de Cuba. La Fiesta Intelectual de la mujer: su actual significado; su misión ulterior. La Habana: Cultural S.A, 1935.

Borrero, Dulce María. Discurso pronunciado en la inauguración de la Biblioteca Pública "José Marti" de Remedios. La Habana: Imprenta Antigua de Valdepares, 1936.

Borrero, Dulce María. Nuevo sentido de la misión del maestro en la Escuela Renovada. Fondo Los Borrero ILL, BOR-D 410.

Borrero, Dulce María. La mujer como factor de la paz. La Habana: Tipografía Modelo, 1938.

Borrero, Dulce María. “Educación pacifista del niño”, en Revista América, año 1, No. 2 (1939): 36-45.

Borrero, Dulce María. "Mi homenaje a la madre: no el cántico, la paz", en El Educador, año. IV, No. 1 (1942): 19-22.

Borrero, Dulce María. Discurso pronunciado en la Facultad de Educación de la Universidad de La Habana. Archivo de la Familia Borrero Pierra.

Borrero, Dulce María. "Libertad: fundamento y esencia de la vida”, en Revista de La Habana, tomo III, año. II, No. 13 (1943): 8-20.

Borrero, Esteban. Lectura de pascuas. La Habana: Imprenta El Fígaro, 1899.

Borrero, Esteban. Don Quijote, poeta. Juguete literario. La Habana: La Moderna Poesía, 1905.

Borrero, Esteban. El amigo del niño. La Habana: La Moderna Poesía, 1905.

Borrero, Juana. Epistolario. La Habana: Academia de Ciencias de Cuba, 1967.

Borrero, Dulce María. Contrato con maestros. Junta de Educación del Distrito Urbano de La Habana, Escuela No. 38, aula No. 1, firmado el 31 de agosto de 1902. Fondo Los Borrero ILL, BOR-D 563.

Guerra Sánchez, Ramiro. “Camino de la escuela”, en Revista Educación, No. 95 (1998): 49-52.

Guerra Sánchez, Ramiro. "El estado actual de la enseñanza primaria en Cuba", en Cuba Contemporánea, Tomo XXVII, año IX, No. 106 (1921): 89-105.

Guerra Sánchez, Ramiro. La educación primaria en el siglo XX. Proceso histórico de la misma en Estados Unidos de América, Gran Bretaña y Cuba. La Habana: Centro Superior Tecnológico, 1955.

Manual o Guía para los exámenes de los maestros cubanos conforme al programa oficial acordado por la Junta de Superintendentes de Escuelas Públicas de la Isla de Cuba. La Habana: Imprenta, Librería y Papelería La Moderna Poesía, 1902. 


\section{REFERENCIAS}

Aguayo, Alfredo. Didáctica de la escuela nueva, La Habana: Ed. Cultural, S.A, 1943.

Bosch, Juan. "Mujeres en la vida de Hostos", en Visiones de Hostos. Caracas: Biblioteca Ayacucho, 1988.

Cartaya Cotta, Perla yJosé A. Joanes Pando. Raíces de la escuela primaria pública cubana. 19021925. La Habana, Editorial Pueblo y Educación. (1996)

Chávez Rodríguez, Justo A. Bosquejo histórico de las ideas educativas en Cuba. La Habana: Editorial Pueblo y Educación, 1996.

Correoso del Risco, Felipe. La escuela rural cubana, su evolución y significación histórico-social. La Habana: Editorial Hermes, 1931.

Darío, Rubén. Obras Completas. La Habana: Biblioteca Rubén Darío, 1955.

Guerra, Ramiro. Rehabilitación de la escuela pública. Un problema vital de Cuba en 1954. La Habana: P. Fernández y Cía, 1954.

Guerra, Ramiro. Fundación del sistema de escuelas públicas de Cuba. 1900-1901. La Habana: Editorial Lex, 1954.

Herrera, Ramón Luis y Mirta Estupiñán. Diccionario de autores de la literatura infantil cubana. Sancti Spíritus: Universidad de Ciencias Pedagógicas (en proceso editorial).

Luz y Caballero, José de la. Aforismos. La Habana: Editorial de la Universidad de La Habana, 1962.

Luzuriaga, Lorenzo. Diccionario de pedagogía. Buenos Aires: Editorial Losada S.A, 1966.

Martí, José. "Peter Cooper". La Nación, Buenos Aires, 3 de junio, en Obras Completas, Editorial Nacional de Cuba, 1964.

Ministerio de Educación. La educación en los cien años de lucha. La Habana: Editorial Pueblo y Educación, 1968.

Montori, Arturo. “La educación en Cuba”, en Cuba Contemporánea, año II, No. 1, mayo-agosto, (1914): 19-60.

Pérez, Louis. El diseño imperial: política y pedagogía en el período de la ocupación de Cuba 1899-1902. La Habana: Ministerio de Educación, 1985.

Poncet, Carolina. "Algunos puntos relativos a la escuela primaria", en Revista Educación, No. 96 (1999): 49-55.

Moreno, Ricardo. “Cuba: historia, escuela, nacionalismo (1902-1930)”, eggn Debates americanos, No. 5-6, enero-dic., (1998): 76-89.

Ricardo, Yolanda. Nueva visión de Dulce María Borrero. La Habana: Editorial Letras Cubanas, 1983.

Varona, Enrique José. Trabajos sobre educación y enseñanza. La Habana: Editorial Pueblo y Educación, 1992.

\begin{tabular}{l|}
\hline $\begin{array}{l}\text { Ricardo, Yolanda. "Dulce María Borrero: Una intelectual plural”. } \\
\text { Revista Historia de la Educación Latinoamericana. Vol. 15, No. 20, } \\
\text { (2013): } 19 \text { - 44. }\end{array}$ \\
\hline
\end{tabular}

